Int. J. Sustain. Dev. World Ecol. 11 (2004) 36-47

\title{
Eco-ethical issues: Self-regulating versus subsidized ecosystems
}

John Cairns, Jr

Department of Biology, Virginia Polytechnic Institute and State University, Blacksburg, USA

Key words: sustainability, eco-ethics, subsidized ecosystems, self-regulating ecosystems

\begin{abstract}
SUMMARY
Sustainable use of the planet requires dependable delivery of ecosystem services at a level necessary to meet the needs of humankind. During the last two centuries, particularly in the twentieth century, ecosystems have been fragmented and stressed in a variety of ways, including biotic impoverishment. Self-regulating ecosystems are capable of maintaining nominative structure and function, including normal variability. Those ecosystems incapable of self regulation will require subsidies, which will divert resources from other activities that may also be important to sustainable use of the planet. If ecosystems are not subsidized, the loss of natural capital and ecosystem services will almost certainly impair the quest for sustainable use of the planet. Although most discussions of sustainability reflect an awareness of humankind's dependence on natural systems, ecosystem self regulation has not received an adequate amount of attention.
\end{abstract}

\section{SELF-REGULATING ECOSYSTEMS}

Self-regulating ecosystems should not be thought of as only technological systems. Regulate means to direct or control by means of a principle. Self regulation in nature is not a conscious effort, but rather the result of resource partitioning in which finite or limited resources are shared by an enormous number of species (30+ million). This distribution means that no single species gets a disproportionate share of the resources and that the wastes of one species are resources for another species. This allocation of resources per species is the result of resource partitioning achieved by a process of co-evolution by quite dissimilar species. For example, nectar is available in a wide variety of flowers of quite different structures. Hummingbirds have evolved an array of bill lengths so that each species is particularly suited to obtain nectar from a flower with a particular structure. As a consequence, a particular resource, nectar, is partitioned because some species are more suited to gathering nectar from certain flowers than others. Species diversity is maintained by conditions that permit the survival of substantial numbers of these co-evolutionary relationships. However, if a particular species of hummingbird disappeared, the nectar would still be available to other nectar gathering species less capable of exploiting the resources of a particular flower.

Furthermore, evolution is always moving toward increasing complexity, which results in finer and finer partitioning of resources. Complexity in nature results in an array of feedback loops, interrelationships, and, most important, use and reuse of resources. This dynamic system keeps everything (e.g. nutrients) moving, and species are also constantly being replaced in a successional process. However, species that disappear from one locale usually appear at another one. Despite this activity, the structure and function of the ecosystem remain remarkably stable, although the ecosystem does vary within limits. This dynamic stability is maintained by the interaction of an array of rate processes. One such interaction that results in an equilibrium number of species has been described by MacArthur and Wilson (1963). Another model of community structure that remains remarkably constant, although the kinds of species do not, is described by Patrick (1949). Illustrative functional attributes are described by Likens and Bormann (1995).

Nature favours quantity, from which it selects quality. Individual species and individual organisms have important roles, always in the context of the interdependent web of life in which all species, including humans, are a part. Often overlooked in the quest for sustainability are the changes required in the direction of humankind's financial investments, the orientation of its technology, the allocation of global resources, and, most important, in our mind set. Emulating the processes of nature is the most direct path to sustainability.

Correspondence: J. Cairns, Jr., Department of Biology, Virginia Polytechnic Institute and State University, Blacksburg, VA 24061, USA 
Nature ensures that its resource reserves are not readily available on demand. Furthermore, systematic recycling and reuse protects nature's inventory of both renewable and nonrenewable resources and keeps them from being pushed beyond critical limits needed for sustainable use. Societal and institutional change must be directed by the ability of natural systems to absorb the effects of human activities. Humankind is ethically responsible for present unsustainable practices and also for instituting the changes necessary to achieve sustainability.

The concept of viewing natural systems as sacred and inviolate will be a shocking or offensive idea to many people. Even acknowledging humankind's dependence upon natural systems will be difficult for many people. Asserting that both exponential and economic growth are unsustainable on a finite planet will be met by ridicule and sarcasm by those people reaping enormous wealth from these practices. However, if humankind lacks the courage and depth of ecological understanding necessary to eliminate unsustainable practices, nature will do so in ways that will cause both the wealthy and poor to suffer.

Earth is an ecosphere and the evolutionary source and support of life. A committee of the Ecological Society of America defined an ecosystem as a spatially explicit unit of Earth that includes all organisms, along with all components of the abiotic environment within its boundaries (Christensen et al. 1996). The term ecosystem was first used by Tansley (1935), who noted that organisms claim society's primary interest. He also stated that, even when research and thinking are on the basic level, organisms cannot be separated from the special environment with which they form one physical system. The National Research Council (1992) states that the goal of restoration is to emulate a natural, functioning, self-regulating (italics mine) system that is integrated into the landscape in which it occurs. It is almost platitudinous to state that a damaged ecosystem is not self regulating and that exemplary ecological restorations have restoring this capability as a major goal. During the recovery phase, effective subsidies will assist the recovery process and reduce the time required to reach the desired state of self regulation. Complex ecosystem functions, with feedback loops and a variety of other attributes, are described in detail in ecology texts and journals. Most functions, arguably all, are involved in the delivery of ecosystem services and the accumulation of natural capital. Since ecosystems are dynamic, there is usually both colonization and decolonization of species as a consequence of seasonal cycles, long-term climatic changes, and the like. Despite all of these activities, ecosystems maintain a dynamic equilibrium and functional performance. It is especially important to remember that self regulation in water ecosystems is dependent upon inputs from the surrounding terrestrial ecosystems.

However, fragmentation of ecosystems by highways, power lines, and the like usually disrupt ecosystem conditions. Pollutants may both eliminate species and reduce their physiological function. Lovelock (1980) illustrated how important these interrelationships are by correctly predicting that no life could exist on Mars because of its inactive atmosphere.

The criteria for determining how many of the planet's ecosystems are self regulating are far from robust. Furthermore, as McNeill (2000) has remarked, in environmental history, the twentieth century qualified as a unique century because of the rapid acceleration of so many processes that bring ecological change. It is possible, arguably probable, that self-regulating systems may disappear before society has detailed knowledge of their attributes. On the other hand, ecosystems are able to recover from damage and, over time, return to a selfregulating state. Still, a prudent society would take precautions to avoid more ecological damage until more is known about both the subsidies needed by recovering ecosystems and those that are unable to recover fully.

\section{EXAMPLES OF SUBSIDIES}

Many species have disappeared or have reduced numbers in regulated rivers in which the flow regime has been altered, the water quality changed, or substantial amounts of water have been removed for irrigation, etc. Partial restoration of the hydrologic regime often restores a substantial degree of ecological integrity, and subsidies may restore some of the antecedent conditions. Of course, most widespread subsidies are applied to agroecosystems, which bear little resemblance to natural ecosystems partly because of the subsidies themselves. Since many agribusinesses favor monocultures, this situation is a golden opportunity for pests. To keep pests under some degree of control, large amounts of pesticides are usually used, as well as biological controls. Both are subsidies. Many of the world's agroecosystems are heavily subsidized by massive deliveries of water diverted from other areas or from fossil water (underground aquifers), which is being used at rates far greater than normal recharge rates. Postel (1999) discusses water subsidies, and a similar volume on water supply problems of the future has been produced by the US National Academy of Sciences et al. (1999). A superb book on perverse subsidies is Myers and Kent (2001). The book has a very extensive list of additional source materials. 
It seems prudent to eliminate or reduce subsidies that have deleterious environmental effects and to prepare to increase further the beneficial environmental subsidies if, as seems quite likely, damage to natural systems continues at a rate equal to or greater than the present rate.

\section{WHO PAYS?}

Ideally, the person or organization that causes environmental damage should pay the costs of ecological restoration and any subsidies during the transition to whatever level of ecological recovery seems possible. In most cases, however, ecological damage is caused by a variety of events, and the guilty party or parties are difficult to determine. In addition, much environmental damage has occurred in countries with very poor economies. If subsidies must originate outside the country where ecological damage has occurred, there will almost certainly be a requirement for persuasive evidence that convincing steps have been taken to prevent the damage from reoccurring. Doubtless, resistance will be strong to this type of subsidy even though there is already a precedent. The International Monetary Fund requires evidence of fiscal responsibility before granting or extending a loan to countries that cannot finance ecological restoration efforts. Why not require evidence of environmental responsibility before granting a subsidy?

The attempt by the United States to clean up hazardous waste sites ('Super Fund') provides ample evidence that assigning responsibility for damage to human health and the environment is very difficult. This situation may be due, in part, to the difficulty of evaluating scientific evidence in the American legal system and of determining the portion of the stress due to each source of pollution.

If the 'Super Fund' experience is representative of untangling a complex web of environmental stressors, where substantial sums (sometimes over half) of money to legal fees and costs rather than rehabilitating the environment, using tax dollars may be more cost-effective. Even if tax dollars were used, effective oversight would be necessary to reduce bureaucratic waste and inertia. This process need not increase an individual's tax burdensubsidies that benefit a few and lead to damage in the environment could be shifted to environmentally beneficial undertakings. The Myers and Kent book (2001) provides much evidence of how and where this could be done. It is highly improbable that, despite the effective analysis carried out by Myers and Kent, they have documented all perverse subsidies that are environmentally damaging.

\section{REDUCING THE TAX BURDEN}

Developing a more mutualistic relationship between human society and natural systems would not only be sound eco-ethics but would also increase the number of self-regulating ecosystems and, thus, the need for subsidies. Human society has become so accustomed to ecosystems having the capability of self regulation that the thought of having to subsidize them in order to maintain and increase natural capital and ecosystem services is shocking. There is no precedent for aiding ecosystem recovery in human history, so why worry about it now? The reason to be worried is the unprecedented assault on ecosystem integrity by human society. Humankind did not experience the ecological disequilibrium that accompanied the five great extinctions as evidenced in the fossil records. The important question becomes: must human society witness a major extinction period to realize that such a happening is plausible, or can intelligence and reason enable humankind to visualize what might happen and take precautions to avoid it? As the eco-ethical relationship improves, the cost of subsidies should ultimately be greatly reduced. One would also be justified in viewing this eco-ethical relationship as an act of enlightened self-interest by humankind, since the ecological life-support system would be self regulating. Ultimately, sustainable use of the planet requires a healthy biospheric (global ecology) life-support system.

\section{LITERACY, REVERENCE, AND SACREDNESS}

Increasing environmental literacy, having a reverence for natural systems, and regarding them as sacred should increase their health, integrity, and capability of self regulation. However, it is quite clear that none of the above are working well since environmental damage is occurring at a rate unprecedented in human history. How can literacy, reverence, and sacredness be improved since all three are essential for humankind to develop an optimal, mutualistic relationship with natural systems? 


\section{Environmental literacy}

Since the United States and Canada have very large ecological footprints in hectares/person (USA 5.1; Canada 4.3) compared to the world (1.8) and India (0.4) (Wackernegel and Rees 1996, their Table 3.4, p. 85) one might reasonably ask 'Does environmental or ecological literacy affect the size of an individual's or country's ecological footprint?' Since the beginning of the twentieth century, the available ecological space per capita has decreased from about 6 ha to approximately 1.5. Kerala, a state in southern India, has a per capita income equivalent to US\$1/day, but the life expectancy, infant mortality, and overall literacy rates are similar to those of the industrialized world. The difference appears to be the degree to which social capital is valued as opposed to manufactured capital (Alexander 1994). One rarely sees paid advertisements on the value of social capital while advertisements extolling the value of manufactured capital are ubiquitous - at least in areas where consumer purchasing power will likely result in sales and profit.

Clearly, a 'more is better' attitude confuses quantity of possessions with quality of life. Since there is a correlation between level of education (as presently defined) and affluence, environmental literacy has not been improved by formal education. As Robin (1994) notes, it is important to focus on personal fulfillment rather than on monetary wealth or acquisition of material possessions, and Menzel (1994) illustrates the poor correlation between material possessions and happiness. His photographs show stark contrasts in the amount of material possessions considered essential by an average family in a number of nations. Yet, despite the strong contrasts in material possessions and the consequent difference in the size of the ecological footprint, humankind still needs to aspire to sustainable use of the planet.

In terms of sustainable use of the planet, environmental literacy prospects are grim. The affluent have large ecological footprints, and the poor have large families. Neither practice is sustainable, but the means to persuade each group to move to more sustainable practices remain elusive. Sustainable use of the planet will require a strong focus on long-term goals that focus on quality of life for future generations.

Formulating and achieving long-term goals will require both overall scientific literacy and an ethos (set of values). However, Kosko (2002) summarizes the findings of a recent US National Science Foundation study in which overall scientific literacy remained fairly low: for example, only $54 \%$ of adults know that Earth takes one year to orbit the sun. At the same time, belief in pseudoscience continues to rise. In the United States, rule of law is prized; however, the study (Kosko 2002) suggests that most adults are not capable of serving on a jury that must decide questions of fact based on scientific or technical evidence. Worse yet, many judges will continue to let dubious 'experts' testify before scientifically incompetent jurors, and only one judge in 20 understands testability and error rate of scientific data.

Literacy was originally defined as the ability to read and write, and this definition is still a major measure of a country's standing (i.e. the number of people who can read and write). Many educational systems now add mathematics, computer science, and the like to the ancient skills. Hardin (1985) defines ecological literacy as the ability to ask 'What then?', and Orr (1992) notes that the failure to develop ecological literacy is both a sin of omission and of commission. Society is failing to teach the basics of how Earth works. As a consequence of the failure to include ecological perspectives in a variety of subjects (history, economics, politics, etc.), students form the impression that ecology is unimportant.

Environmental/ecological literacy, which is essential for taking the steps necessary to produce selfregulating ecosystems or to understand when ecological subsidies are needed and what they should be, is seriously deficient. Moreover, no societies are sufficiently far advanced in sustainable practices to serve as role models for either ecological literacy or sustainable use of the planet. Environmental literacy must be developed to the point that it enables both sustainable development and protection of self-regulating ecosystems and provides adequate ecological subsidies when restoration to a self-regulating condition is not possible.

\section{Reverence}

Scientific results will always contain some uncertainty since they are probabilistic estimates based on evidence that is rarely perfect. If humankind revered (held in great regard) natural systems, it would be inclined to do everything possible to protect their health and integrity and restore them if evidence indicated this was desirable. Using good judgment, living responsibly, and feeling compassion for other life forms and living members of the human species and their descendants are the sine qua non of sustainable use of the planet. Humankind must have a reverence for these attributes because they are essential to the sound value judgments needed to complement scientific evidence. In short, humankind needs to stop managing the planet as if it were a multinational corporation and manage societal practices to protect something society reveres (i.e. natural systems). Humankind needs natural 
systems more than they need humans, although those who believe in no limits to growth, no such concept as carrying capacity, and no resource limits, think otherwise. The problem has been that replacing the failed systems with economic growth as the primary goal, rather than sustainable use of the planet, may not be very effective long term.

Part of the problem is confusion about sustainability. In 1948, my mentor Ruth Patrick described the ideal relationship of humankind with natural systems as 'use without abuse.' These three words say it all. Humans are part of the interdependent web of life, so it is inherent to interact, or 'use' it. Abusing the web will tear its fabric and harm humankind. Brown et al. (1990) described a sustainable society as one that satisfies its needs without jeopardizing the prospects of future generations. Although the authors clearly intend the protection and reverence for natural systems, this intent should have been explicitly stated in the primary definition. The quest for sustainability requires that humankind revere natural systems if only because it is dependent upon them. The widely cited Brundtland report (World Commission on Environment and Development 1987) states that development is sustainable if it meets the needs of the present without compromising the ability of future generations to meet their own needs. However, the report does not adequately stress humankind's dependence on the planet's ecological life-support system, nor such important ecological concepts as carrying capacity or a nonlinear response after an important ecological threshold has been crossed. Revering the needs of natural systems is a prerequisite for meeting the needs of future generations of the human species. As Orr (1992) remarked, the World Commission hedged its bets between two versions of sustainability: (1) technological sustainability (can human society achieve sustainability through better technologies and more accurate prices?) and (2) ecological sustainability (finding alternatives to the practices that harmed ecosystem integrity). The second, ecological sustainability, requires that humans revere (hold in great regard) both the structure and function of natural systems. There is no reason why a mutualistic relationship between the two systems cannot be developed, but the needs of the ecological systems must be given at least as much attention as the needs of the technological/economic system.

\section{Sacredness}

If Earth were regarded as holy, there would be more impetus to the quest for sustainability because the ecological life-support system would be regarded as sacred. Everything possible would be done to avoid profaning it.

\section{ECO-ETHICALLY DRIVEN SUSTAINABLE USE OF THE PLANET}

If there were increased literacy and a reverent and sacred attitude toward natural systems, then some straightforward steps that could be implemented immediately:

(1) Renewable resources would only be used at rates that ensure they would remain intact. Fisheries would not be over harvested, ground water aquifers would not be used at greater than recharge rates, and areas with depleted natural capital would be 'rested' until the natural capital could be restored.

(2) Ecological restoration would be carried out at rates at least equal to the rates of ecological damage. This view sounds utopian, but ecological destruction must stop sometime, why not now before nature's sanctions that enforce carrying capacity limits become very obvious? Still, an even more utopian idea is that economic/technological strategies, both extremely new in evolutionary time, will work despite a growing population and increased per capita material affluence. However, ecological restoration is often more swift than ecological restoration. Ecosystems can be damaged in hours, e.g. by oil spills and other hazardous materials; however, restoring damaged ecosystems may take years, decades, or centuries, and even then they may not resemble the predisturbance condition. Case histories of restoration sites furnish clear evidence of local civic pride in restoration efforts (National Research Council 1992). Ecological restoration is a global need that is the aggregation of local, regional, or national damage to ecosystems. However, effective solutions must occur at the local level, otherwise the integrity of the restored ecosystem will not be protected.

(3) Ecological restoration must be primarily local or regional. Berry (1989) believes that limits exist to the ability to comprehend and, thus, coordinate entities beyond a certain scale. He further asserts that humankind has a limited sense of good and any willingness to do it. How, then, will a constituency for ecological restoration develop? At present, at least half the planet's population lives in urban or 
suburban areas where frequent contact with natural systems is usually quite difficult. Persons who have become disengaged from nature must somehow become re-engaged-if not physically, then at least spiritually. Redclift (1987) believes that humankind must embrace the ways in which indigenous peoples structure their knowledge of their environment. Both the Natural Step Program (Robèrt et al. undated) and concepts of natural capitalism (Hawken et al. 1999) offer hope in this regard. A single model does not fit all ecoregions, and sustainable use of the planet requires both preservation and accumulation of natural capital, as well as the ecological and cultural practices that foster preservation and accumulation. Lovins and Lovins (1982) recommend using ecological concepts for the design of resilient technological systems. Both ecological and technological resilience is predicated upon the capacity to withstand both external disturbances and internal malfunctions. Ecological systems retaining resilience are not efficient as the term is used in modern industrial society (e.g. functional redundancy is common in self-regulating systems).

\section{THE IMPORTANCE OF A SENSE OF PLACE}

A strong sense of place and a reverence for local or regional natural systems is also mandatory for sustainable use of the planet. Developing a long-term commitment to the preservation of an area one is familiar with is easier than caring for regions with which one has little contact. A classic literary example of this sense of place is Thoreau's Walden Pond.

With the inspired leadership of local high school teacher Tom Furrer, a group of Casa Grande High School students in Petaluma, California, raised money to clean up and restore Adobe Creek, which once had a salmon run (as described in Cairns 1999). Adopting a damaged ecosystem to restore would be a superb way for each community to develop a more harmonious relationship with natural systems. Such undertakings should involve all age groups, income levels and the like. In order to achieve sustainable use of the planet, all citizens must be able to understand the difference between self-regulating ecosystems, subsidized ecosystems, and damaged ecosystems. This knowledge alone will require massive participation and long-term commitment.

Of course, all these efforts will be virtually useless if people limit their dedication to one particular ecosystem while ignoring events in their bioregion. Of course, the interest level must not be trivial, e.g. one day a year is designated 'Earth Day,' in the United States-speeches are made, songs are sung, a few trees are planted; the next day is 'business as usual.' Ecosystem services are expected to continue, but public involvement to protect the ecosystems that provide these services is not exemplary. Since the ecosystems constitute the planet's ecological life-support system, this lack of involvement is a flagrant denial of reality.

\section{CARRYING CAPACITY}

The greatest peril to human society is seldom discussed. At its core is the concept of the planet's finite carrying capacity for humans. A related issue is what time human artifacts will displace natural systems to the point that they no longer furnish the ecosystem services essential to the survival of humankind. Reduction in ecosystem services will constitute a reduction in carrying capacity. However great the displacement of natural systems by human artifacts, there is a strong probability that natural systems will rediversify after an extinction, as has happened after previous mass extinctions. It is, therefore, not only an ethical responsibility to protect and restore natural systems, but it is also an act of enlightened self-interest since natural systems constitute humankind's life-support system. In short, humankind needs natural systems, but they do not need humans since natural systems existed for billions of years before humans arrived.

Surprisingly, although human society does not appear to be deeply concerned about the failure of its ecological life-support system (I am well aware of the many fine publications on this subject, but society as a whole either does not believe them or, more commonly, is unaware of them), it is almost obsessed with the health of its economic/technological system. It seems senseless to abandon concern for the biospheric life-support system when there is robust evidence that it can be self regulating if human assaults upon its integrity are restrained.

The economic/technological system has only been operative for about 10000 years (beginning with the agricultural revolution) and has only been in major operation for the last two centuries - a tiny span of evolutionary time. The economic/technological system treats natural systems as commodities, not as the life-support system upon which human society is dependent.

Of course, both systems could fail and could even do so simultaneously. For example, a major climate 
change affecting agribusiness and changes in the hydrologic cycle will almost certainly affect both systems. Resiliency of both systems should be increased as a precautionary measure. Self-regulating ecosystems have equitable energy allocation, functional and structural redundancy, closed loops, and large numbers of species represented by low numbers of individuals. Thus, the temporary loss of a few, or even a significant number, of species can be tolerated as a consequence of various redundancies. However, long-term stability of an ecosystem depends on a constant colonization by new species, which can be in a dormant stage at the site itself or an invader from other sites. Most ecosystems probably have a combination of these two phenomena to facilitate both cyclic and successional species turnover. Species invasion and successful colonization by the necessary number of species is enhanced for species from other sites if the travel distance is minimal and the travel route is tolerable (e.g. no pollution stress). This dynamic process is enhanced by a decentralization of the total species pool and obstructed by ecosystem fragmentation of species from one ecological 'island' to other 'islands.'

Sustainable use of the planet requires a significant number of self-regulating ecosystems that let colonization and natural selection maintain ecosystem integrity. If an ecosystem subsidy is necessary, there must be a better understanding of natural processes, a reverence for them, and a willingness to provide these subsidies for as long as they are necessary to keep ecosystems as functional as possible, including the delivery of ecosystem services. Since humankind at its present population size, distribution, and level of affluence is dependent on both technological and ecological life-support systems, it is important that the structure and function of natural systems be replicated as far as possible (Todd and Todd 1984).

\section{ROLE OF BIODIVERSITY}

Arguably, the greatest unknown is the role of biodiversity in ensuring self-regulating ecosystems. Succession or turnover of species in all ecosystems exists, although the temporal spans for the rate of turnover may differ dramatically from one ecoregion to another. Society does not yet know how many species are needed to preserve the integrity of self-regulating systems (Cairns 2002) or what species are being lost and at what rates. Even if financial support were available for determining the rate of replacement in temporal spans of a one-century monitoring system, not enough trained personnel exist to carry out this endeavor in a scientifically responsible manner, although a number could be educated and trained over a period of years.

\section{BIOMONITORING}

Biomonitoring is surveillance undertaken to ensure that previously established quality control conditions are being met (Cairns 2002). This definition of monitoring is common in hospital intensive care wards, industrial production lines, and a variety of other situations.

Since the number of species and structure of communities will be difficult to use in developing a monitoring strategy, an alternative strategy would be to monitor the integrity and health of ecosystems and to assume that, if the services they are providing remain fairly constant, the requisite number of species are present. One of the weaknesses of this assumption is that some greatly diverse systems appear to have a significant amount of functional redundancy; therefore, the ecosystem may continue to function so well that the monitoring system will not be able to distinguish between normal variability and a decline in trend. Of course, monitoring of species of particular interest to human society should be encouraged, particularly those threatened with or nearing extinction. One of the major drawbacks in the functional approach just mentioned (i.e. integrity, health, and ecosystem services) is that ecosystems may only need substantial levels of biodiversity for episodic periods of stress and may be able to function quite well under normal conditions without the species reserve. Thus, even if the ecosystem seems to be normal in terms of functional capabilities, it may not be normal in terms of biodiversity.

\section{THE RELATIONSHIP BETWEEN STRUCTURE AND FUNCTION}

Three major possibilities exist in the relationship between structure and function:

(1) Structure and function of natural communities are so closely interrelated that it is impossible to change one without changing the other,

(2) Structure (i.e. number and distribution of species) is more sensitive than function because functional redundancy will compensate for loss of species to a certain degree, and 
(3) Function is more sensitive than number of species because it is possible, at least in the short term, to diminish species function and well being without actually killing the species.

The latter is common in ecotoxicological tests when endpoints (e.g. respiratory function, swimming ability, visual acuity, and the like) other than death are used.

\section{FALSE NEGATIVES AND FALSE POSITIVES}

Biological monitoring systems are generally designed to provide an early warning of change so that remedial measures may be taken as soon as possible. All monitoring systems are plagued with false positives and false negatives. A false negative is a signal indicating no deviation from the quality control norms has occurred when, in fact, change has occurred. A false positive is a signal indicating a definite deviation from the previously established norms, when none has occurred. False positives and false negatives should be expected when a monitoring system is being established unless normal variability is well understood. Trend analysis should be based on attributes that are not likely to demonstrate high variability, are not likely to disappear as a result of normal successional processes, have high predictive value for other attributes, and are likely to be persuasive to both the scientific community and policymakers. Use of inappropriate or unstable attributes for long-term trend analysis is most unfortunate since each shift causes a 'down time' during which the trend analysis is ineffective or partially so. Regrettably, this instance may be the time it is most needed.

\section{THE ROLE OF EDUCATION}

If both natural capital and ecosystem services are essential to sustainable use of the planet, then preserving selfregulating ecosystems and subsidizing those in need of help become an urgent matter. Educational systems must include sustainability as a part of each course. The task is not as formidable as it sounds. Years ago, several graduate students and I helped acquaint a high school teacher and his class with the fundamentals of ecological restoration. The particular ecosystem chosen as a class project was a landfill fairly close to a historic park and a scenic parkway. A landfill, for those not familiar with this particular word, is a place where all of the refuse of society is taken and buried. This includes all items not presently being recycled in some way and at some times classified in general as household waste, although many landfills contain industrial and municipal waste as well. In this particular landfill (seven or eight years ago), the wastes were compacted, baled, and stacked neatly. This refuse was then covered with clay or other materials to reduce water penetration and then a layer of topsoil to encourage revegetation. Not surprisingly, the students were horrified at the amount of waste arriving in truckload after truckload. We encouraged these students to determine how much refuse each of their households produced and what the average was for each household in the urban area. This awareness is, of course, one of the essential steps to achieving sustainable use of the planet.

The main purpose of the class project, however, was to determine what type of ecological restoration would be most appropriate once the landfill was sealed. The students conducted individual component investigations on what kind of plants could survive the initial planting in the landfill soil and would hold the soil together and keep it from eroding. The lesson from this project was two-fold: students were appalled by the amount of the waste produced by a 'throwaway society' and were encouraged by the fact that they could do something to restore the ecosystem, if only partially, that had been removed to create the landfill.

Younger people are understandably apprehensive about their futures and enthusiastic whenever they have an opportunity to do something likely to improve their future quality of life. Although they may not know the term 'sustainable use of the planet,' they are well aware that humankind as a whole is living unsustainably, either by having large ecological footprints or large families or, in some cases, both. Educational systems can teach these young people about ecology and sustainable use of the planet. Ecological restoration, especially of a nearby damaged ecosystem, requires no highly technical equipment, although occasionally some regrading or redistribution of soil might be necessary. There are, in fact, no major obstacles to reestablishing an intimate relationship with natural systems at all levels in the educational system and, eventually, in all parts of society. The costs are minimal, except in personal time and energy. Achieving sustainable use of the planet will require a level of ecological literacy in every individual far greater than what now exists (Orr 1992), and universities and other institutions of higher learning need to practice what they teach, particularly with regard to concepts of ethics and social behavior (Filho and Wright 2002). 


\section{ECO-ETHICAL MOTIVATION}

Although some students are highly motivated to restore damaged ecosystems, most are not; this lack of motivation is a serious barrier to achieving sustainable use of the planet. Navratil (2002) reports on a study to determine what it would take to get youth, aged 18-24, to vote in an American national election. The incentives offered in the study were: free beer, a few good speeches, a lottery ticket for a red Corvette (a sporty automobile), or another Vietnam war (which provoked major student resistance in its era). The red American classic automobile lottery ticket won. One student appears to have identified the problem —-many issues do not affect you when you are 18-24. Caring about sustainable use of the planet is in the same category as voting. Clearly, the educational system has failed to instill the importance of long-term issues.

Of course, all age groups must be involved in the quest for sustainability. Lack of motivation is not a unique attribute of 18-24 year olds. Rather, it is a ubiquitous attribute. All age groups must be motivated toward sustainability, but it is essential that younger people be highly motivated because they have most of their lives ahead of them.

\section{JUSTIFICATION FOR BOTH CONCERN AND OPTIMISM}

Undertakings such as sustainable power, sustainable transportation, sustainable agriculture, sustainable cities, sustainable range management, and sustainable fisheries are all homocentric-they focus on human 'needs'. However, sustainable use of the planet requires an ecocentric perspective. At the present rate of ecological damage, many, possibly all, self-regulating ecosystems will be lost. The sort of subsidy that would be needed to assist enormous ecosystems, such as the oceans, boggles the mind. Even if enlightened subsidies were available, self regulation might not be restored in a time frame of interest to humans. Furthermore, the natural capital and ecosystem services might well diminish appreciably during this period.

The outlook for terrestrial systems is also not encouraging, but there are some grounds for optimism. More information is available on the restoration of terrestrial ecosystems, but not much evidence is available on what self-regulating ecosystems look like. Information is not available for each ecosystem in each ecoregion; consequently, development of both theory and practice will require much time and energy on local, national, and global levels.

This massive undertaking (sustainable use of the planet) can only be successful if humankind's dependence on ecological life-support systems is widely recognized. Once the dependence of humankind on these ecological life-support systems is accepted, they should be treated as inviolate (i.e. sacred). The personnel and resources would then be dedicated to protect those ecosystems deemed self regulating and those requiring subsidies, including ecological restoration. Given the momentum of the present economic/technological system that preserves neither natural capital nor ecosystem services, it seems probable that some major catastrophic event will be necessary to initiate any change in attitude toward natural systems.

\section{CONCLUSIONS}

Humankind is dependent on both natural systems and the ecological services they provide for achieving sustainable use of the planet. The ecological services of natural systems have been free and constant, regardless of the encroachments and damage inflicted upon them by humans. However, a number of ecological thresholds and breakpoints, when crossed, often result in a nonlinear response that may occur with breath taking rapidity. Even though some systems have sufficient ecological resiliency to allow crossing some thresholds reversible, human social systems and their response times may not be adequate to this end. One of the basics for ensuring the continual availability of natural capital and ecosystem services is to protect self-regulating ecosystems wherever they exist. In addition, subsidies that will enable the accumulation of natural capital and the provision of ecosystem services for those ecosystems that are not now self regulating must be determined. Even if ecological restoration cannot produce a self regulating system for a variety of reasons, restoration should significantly reduce the subsidy requirements. Humankind is currently unprepared for this responsibility. Success in this endeavor will depend heavily on the development and practice of eco-ethics and on achieving a higher level of environmental literacy than now exists in human society, particularly in the case of its leaders. The planet's natural systems can handle only so much pressure, and time is growing short. 


\section{ACKNOWLEDGEMENTS}

I am indebted to Eva Call for transcribing the handwritten and dictated portions of the first draft of this manuscript and to Darla Donald for editorial assistance with subsequent drafts and preparation for publication in this journal. The Cairns Foundation paid for processing costs for this manuscript.

\section{REFERENCES}

Alexander WM. Humans sharing the bounty of the Earth: hopeful lessons from Kerala. A paper prepared for the International Congress on Kerala Studies in Thiruvanathapurum, Kerala. In: Wackernagel M and Rees W. Our Ecological Footprint: Reducing Human Impact on the Earth. Gabriola Island, British Columbia, Canada: New Society Publishers; 1996:23

Berry W. The futility of global thinking. Harper's Magazine, 1989;Sept

Brown L, Flavin C. and Postel S. State of the World. New York: WW Norton; 1990:173-81

Cairns J, Jr. Can human society exist without ecological restoration? In: Halbert JE and Chang CL (eds), Proceedings from the 1998 Appalachian Ecological Integrity Conference. Elkins, WV: Heartwood; 1999:2031

Cairns J, Jr. Environmental monitoring for the preservation of global biodiversity: the role in sustainable use of the planet. International Journal of Sustainable Development and World Ecology 2002;9:135-50

Christensen NL, Bartuska AM, Brown JH, Carpenter C, D'Antonio C, Francis R, Frankin JF, MacMahon JA, Noss $\mathrm{RL}$, Parsons DJ, Peterson CH, Turner MG and Woodmansee RG. The report of the Ecological Society of America Committee on the Scientific Basis for Ecosystem Management. Ecological Applications 1996;6:665-91

Filho WL and Wright TSA. Barriers on the path to sustainability: European and Canadian perspectives in higher education. International Journal of Sustainable Development and World Ecology 2002;9:179-86

Hardin G. Filters Against Folly. New York: Penguin Books; 1985

Hawken P. The Ecology of Commerce: A Declaration of Sustainability. New York: Harper Business Publications; 1993

Hawken PA, Lovins A. and Lovins H. Natural Capitalism: Creating the Next Industrial Revolution. New York: Little, Brown; 1999

Kosko B. Junk science pervades the courtrooms. The Roanoke Times 2002; June 7:A15

Likens GE and Bormann FH. Biogeochemistry for a Forested Ecosystem, 2nd ed. New York: Springer-Verlag; 1995

Lovelock J. The Ages of Gaia. New York: WW Norton; 1980

Lovins AB and Lovins LH. Brittle Power: Energy Strategy for National Security. Andover, MA: Brick House Publishers; 1982

MacArthur R and Wilson EO. An equilibrium theory of insular biogeography. Evolution 1963;17:373-87

McNeill JR. Something New Under the Sun: An Environmental History of the Twentieth-century World. New York: WW Norton; 2000

Menzel P. Material World: A Global Family Portrait. San Francisco, CA: Sierra Club Books; 1994

Myers N and Kent J. Perverse Subsidies: Tax \$s Undercutting Our Economies and Environment Alike. Washington, DC: Island Press; 2001

National Research Council. Restoration of Aquatic Ecosystems: Science, Technology, and Public Policy. Washington, DC: National Academy Press; 1992

Navratil W. Free beer not enough motivation for voters. The Roanoke Times 2002;Nov 3:A-1, A-4

Orr DW. Ecological Literacy: Education and the Transition to a Postmodern World.(Albany, NY: State University of New York Press; 1992

Patrick R. A proposed biological measure of stream conditions based on a survey of the Conestoga Basin, Lancaster County, Pennsylvania. Proceedings of the Academy of Natural Sciences Philadelphia 1949;101:277-341

Postel S. Pillar of Sand: Can the Irrigation Miracle Last? New York: WW Norton; 1999

Redclift M. Sustainable Development: Exploring the Contradictions. New York: Methuen Publications; 1987

Robèrt K-H, Daly H, Hawken P and Holmberg J. Compass for sustainable development. Stockholm: The Natural Step Environmental Institute, undated

Robin V. A Declaration of Independence-From Overconsumption. Seattle, WA: The New Road Map Foundation; 1994 
Tansley AG. The use and abuse of vegetational concepts and terms. Ecology 1935;16:284-307

Todd J and Todd N. Bioshelters, Ocean Arks, City Farming: Ecology as the Basis of Design. San Francisco, CA: Sierra Club Books; 1984

US National Academy of Sciences, Royal Scientific Society of Jordan, Israel Academy of Sciences and Humanities, and Palestine Academy for Science and Technology. Water for the Future: The West Bank and Gaza Strip, Israel, and Jordan. Washington, DC: National Academy Press; 1999

Wackernagel M and Rees W. Our Ecological Footprint: Reducing Human impact on the Earth. Gabriola Island, British Columbia, Canada: New Society Publishers; 1996

World Commission on Environment and Development. Our Common Future. New York: Oxford University Press; 1987 